\title{
Revisiting the Origin of the Octoploid Strawberry
}

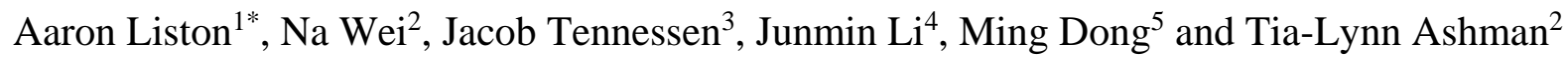

${ }^{1}$ Department of Botany and Plant Pathology, Oregon State University, Corvallis, Oregon, USA

${ }^{2}$ Department of Biological Sciences, University of Pittsburgh, Pittsburgh, Pennsylvania, USA

${ }^{3}$ Department of Immunology and Infectious Diseases, Harvard T. H. Chan School of

Public Health, Boston, Massachusetts, USA

${ }^{4}$ Zhejiang Provincial Key Laboratory of Plant Evolutionary Ecology and Conservation, Taizhou

University, Taizhou, China

${ }^{5}$ Key Laboratory of Hangzhou City for Ecosystem Protection and Restoration, College of Enviro

nmental Life Sciences, Hangzhou Normal University, Hangzhou, China

*e-mail: aaron.liston@oregonstate.edu 


\begin{abstract}
The cultivated strawberry, Fragaria $\times$ ananassa, originated in France approximately 270 years ago via hybridization between two wild species introduced from North and South America. Both the cultivated strawberry and its parental species are octoploids with $2 n=8 x=56$ chromosomes. In the recent publication of the genome of the cultivated strawberry, the authors present a novel phylogenetic hypothesis, proposing that each of the four subgenomes originated from a different $2 n=2 x=14$ diploid progenitor. They further suggest that the hexaploid species Fragaria moschata was a direct ancestor of the strawberries. We reanalyzed the four octoploid subgenomes in a phylogenomic context, and found that only two extant diploids were progenitors, a result that is consistent with several previous studies. We also conducted a phylogenetic analysis of genetic linkage-mapped loci in the hexaploid F. moschata, and resolved its origin as independent of the octoploids. We identified assumptions in their tree-searching algorithm that prevented it from accepting extinct or unsampled progenitors, and we argue that this is a critical weakness of their approach. Correctly identifying their diploid progenitors is important for understanding and predicting the responses of polyploid plants to climate change and associated environmental stress.
\end{abstract}

\title{
Introduction
}

The publication by Edger et al. ${ }^{1}$ of the first chromosome-scale genome assembly of the octoploid strawberry Fragaria $\times$ ananassa cultivar 'Camarosa' represents a significant scientific advance and provides a foundational resource for this important cultivated plant. The authors also identified four diploid species of Fragaria as the progenitors of the wild octoploid species of strawberry (Table 1, Fig. 1a). Three of these species are distributed in Asia, the fourth in western 
North America. Edger et al. ${ }^{1}$ further hypothesized that the hexaploid species $F$. moschata "may be evolutionary intermediate between the diploids and wild octoploid species". This predicts that the hexaploid's three subgenomes should correspond to these three Asian diploid ancestors (Fig. 1a).

\section{Results and Discussion}

Since these phylogenetic conclusions conflict with several recent studies ${ }^{2-4}$ (Table 1), we conducted two new analyses: a chromosome-scale phylogenomic analysis of the four $F$. ×ananassa subgenomes (Fig. 1b,c; Table 2, Figs. 2-3) and a phylogenetic analysis of genetic linkage-mapped loci in F. moschata (Figs. 4-5). We evaluated the phylogenetic hypotheses of Edger et al. ${ }^{1}$ using topology tests and found no evidence of $F$. nipponica and $F$. viridis ancestry in the octoploid (Table 3) and supported independent origins of the hexaploid and octoploid strawberries (Table 4).

We believe that the "phylogenetic analysis of subgenomes" tree-searching algorithm (PhyDS) developed by Edger et al. ${ }^{1}$ was responsible for the unsupported identification of $F$. nipponica and F. viridis ancestry for the octoploids. Their analysis was based on 8,405 individual gene trees compiled from the annotation of the newly assembled octoploid genome and 31 transcriptomes from 12 diploid Fragaria species. In each gene tree, when multiple octoploid genes resolved as sister to the same diploid, these were treated as in-paralogs, and ignored. This forces each of the four octoploid subgenomes to have a different diploid ancestor, an assumption that is at odds with most classical genetic hypotheses for the octoploid ancestry (reviewed in ref. ${ }^{5}$ ) as well as the results of molecular phylogenetic analyses of Fragaria $^{2-4}$. 
In effect, Edger et al. ${ }^{1}$ only considered gene trees as informative when genes from a single octoploid and diploid comprise an exclusive clade. This is an effective strategy for subgenomes A and B (Table 1), where a high proportion of PhyDS resolved gene trees (their Supplementary Table 8) and 100-kb windows (labelled "sister" in Fig. 1c) resolve these with $F$. vesca and $F$. iinumae, respectively. However, the approach fails for subgenomes C and D (Table 1) where a smaller percentage of PhyDS accepted gene trees (their Supplementary Table 8), and very few 100-kb windows (Fig. 1c), resolve an exclusive clade relationship between these subgenomes and $F$. nipponica and $F$. viridis, respectively.

The rationale of Edger et al. ${ }^{1}$ for treating in-paralogs in this way was to avoid errors when homeologous exchange has "replaced" the syntelog of one subgenome with another, as illustrated in their Supplementary Figure 8c. According to their Supplementary Table 10, 11.4\% of the genome has experienced homeologous exchange, suggesting that $90 \%$ of the syntelog gene trees should correctly resolve subgenome ancestry. In contrast, only ca. 3\% of syntelogs across the genome resulted in a subgenome assignment by PhyDS. This indicates that their in-paralog exclusion criterion was too strict. Our results suggest that the great majority of trees rejected by PhyDS resolved F. iinumae as the diploid progenitor of three subgenomes (Fig. 1b, Fig. 2, Supplementary Table 2). This topology matches the examples of "incorrectly identified as progenitor" in their Supplementary Figure 8c, but in our view reflects the most likely evolutionary scenario for the origin of the octoploid strawberries. 
Our phylogenomic approach found that $12.5 \%$ of the genome has experience homeologous exchange (Fig. 1c, Table 2), similar to the Edger et al. estimate of $11.4 \%$. Although none of the 2191 trees from 100-kb windows across the genome (Table 4) match the Edger et al. hypothesis (Fig. 1a), a small number do resolve subgenome $\mathrm{C}$ or subgenome $\mathrm{D}$ with the diploid species $F$. nipponica and F. viridis, respectively (Fig. 1c, Supplementary Table 2). However, these are similar to the number of trees that resolve the opposite species, or F. nilgerrensis, as the most closely related diploid. We suspect that these results can be attributed to incomplete lineage sorting.

In $81.4 \%$ of the 2011 trees where subgenome A (Camarosa vesca) was resolved with the $F$. vesca clade, its most recent common ancestor or sister taxon was $F$. vesca subsp. bracteata (Supplementary Table 2), native to northwest North America. This is consistent with the PhyDS results of Edger et al. ${ }^{1}$, and most previous studies ${ }^{2-4,6,7}$. Likewise, our results and previous studies resolve subgenome B (Camarosa iinumae) with $F$. iinumae from Japan. Subgenomes C and D are most commonly resolved as sister to each other (Fig. 1b, Fig. 2), and may represent an autotetraploid ancestor ${ }^{2}$, although this requires cytogenetic confirmation. Fragaria iinumae is the closest diploid progenitor of these two subgenomes (Fig. 1c, Fig. 3). Whether they originated with an extinct species ${ }^{8}$ or an unsampled population of $F$. iinumae (e.g. from Sakhalin Island) remains to be determined. The origin of the wild octoploid strawberry species likely occurred in Pleistocene Beringia, which is temporally consistent with the estimated age of the octoploids ${ }^{6,9}$ and spatially intermediate between the extant diploid ancestors. 
We also find no support for the Edger et al. ${ }^{1}$ hypothesis that the hexaploid $F$. moschata is a direct ancestor of the octoploids (Table 3, Figs. 4-5). Instead, its progenitors appear restricted to the "vesca clade" (F. vesca, F. mandshurica, F. bucharica).

Polyploidy is increasingly being recognized for its role in generating novel diversity in organismal evolution ${ }^{10}$, and the differential retention of diploid progenitors' genes is central to this process. In particular, these diploid progenitors have each experienced a unique set of environments, pathogens and other challenges to survival, so prior to coming together in a polyploid genome, each progenitor independently evolved "answers" to a diverse array of abiotic and biotic conditions. Understanding the biology of these diploid species can inform polyploid plant adaptation to changing climate and associated environmental stress ${ }^{11}$. For these reasons, it is critical to correctly identify the diploid progenitors of polyploids.

\section{Materials and Methods}

Illumina sequencing libraries were prepared from leaf tissue of six diploid Fragaria species, and 9-32X genomic coverage was obtained (Table 2). Fragaria vesca subsp. bracteata, F. iinumae and $F$. nipponica were sequenced at the Oregon State University Center for Genome Research and Biocomputing Central Services Lab with 100 bp single ends on a HiSeq 2000. Fragaria mandshurica, F. nilgerrensis and F. nipponica were sequenced at Berry Genomics (Hangzhou, China) with $150 \mathrm{bp}$ paired ends on a HiSeq 2000. We removed adapters and low-quality portions of reads using Trimmomatic ( $\mathrm{v} 0.35)^{12}$ and settings LEADING:20, TRAILING:20, SLIDINGWINDOW:5:20, MINLEN:50. The genome assemblies of octoploid Fragaria ananassa 'Camarosa' and diploid outgroup Potentilla micrantha ${ }^{13}$ were downloaded from the 
Genome Database for Rosaceae (https://www.rosaceae.org/). The former was subdivided by the Edger et al. ${ }^{1}$ based on diploid subgenome assignment into four sets of seven chromosomes. The outgroup and subgenome assemblies were converted to $20 \mathrm{X}$ genomic coverage of random 100 bp sequences using BBTools randomreads.sh (https://jgi.doe.gov/data-and-tools/bbtools/). The above sets of sequence reads were aligned with BWA (v 0.7.12) ${ }^{14}$ to the Fragaria vesca $\mathrm{v} 4.1$ genome assembly ${ }^{15}$ after masking with the $F$. vesca $v 4.1$ transposable element library downloaded from the Genome Database for Rosaceae (https://www.rosaceae.org/).

The twelve resulting alignments were converted to a variant call format (vcf) file with SAMtools (v 1.9) ${ }^{16}$ with the default settings of the mpileup and call options. The vcf file was converted into a multisample variant format (mvf) file using MVFtools (v 0.5.1.4) ${ }^{17}$. All heterozygous sites were converted to $\mathrm{N}$, to account for the fact that the octoploid subgenome and outgroup sequences were derived from haploid genome assemblies. MVFtools was used to automate maximum-likelihood (ML) estimates of phylogeny using RAxML (v 8.2.12) ${ }^{18}$ with the GTR $+\Gamma$ model of sequence evolution and 100 bootstrap replicates. A taxon was excluded from the analysis of a $100 \mathrm{~kb}$ window if it had $<10 \%$ of aligned sites. Analyses were conducted for the seven base chromosomes (Fig. 1b, Fig. 2) and for 2191 non-overlapping windows of $100 \mathrm{~kb}$ across the seven chromosomes (Fig. 1c, Fig. 3, Supplementary Table 1). The phylogenetic position of each subgenome relative to diploid species was recorded (see Fig. 3 for details) and summarized for each base chromosome (Supplementary Table 1). Homeologous exchange was inferred when the 'Camarosa vesca' subgenome shared a MRCA with $F$. iinumae or when the other three subgenomes shared a MRCA with the $F$. vesca clade ( $F$. vesca, F. mandshurica, $F$. bucharica). 
We used an $\mathrm{F}_{1}$ cross for linkage mapping of the hexaploid $F$. moschata. Our $\mathrm{F}_{1}$ mapping population was derived from two parental plants collected from Slovenia $\left(46.6827^{\circ} \mathrm{N}\right.$, $\left.16.2951^{\circ} \mathrm{W}\right)$. Following our previous protocols ${ }^{8}$, seeds of the experimental cross $(N=192)$ were planted in a custom soil mixture $(2: 1$, Fafard $4:$ sand top-dressed with Sunshine Redi-earth Plug \& Seedling; Sun Gro Horticulture, Agawam, MA, USA), and grown under $16{ }^{\circ} \mathrm{C} / 21{ }^{\circ} \mathrm{C}$ night/day temperatures and a 14-h photoperiod in a growth chamber at the University of Pittsburgh for $11 \mathrm{wk}$. We selected a random subset $(N=46)$ of the $\mathrm{F}_{1}$ progeny for targeted sequence capture.

Targeted sequence capture was performed using previously developed Fragaria baits (v 2.0) ${ }^{8,19}$. These 20,000 capture baits of 100 bp each are relatively randomly distributed across the seven base chromosomes (1-7). DNA was isolated from silica-dried leaf tissue of the 46 progeny and two parents at Ag-Biotech (Monterey, CA). We constructed individually indexed genomic libraries using the NEBNext Ultra DNA Library Prep Kit (New England BioLabs, Ipswich, MA, USA), which were then target enriched ${ }^{8}$ and sequenced using a 1/3 lane of 150 bp paired ends on a HiSeq 3000 at the Oregon State University Center for Genome Research and Biocomputing Central Services Lab.

The hexaploid linkage mapping involved four steps: quality filtering of paired-end capture reads, mapping reads to the above-mentioned diploid $F$. vesca $\mathrm{v} 4.1$ genome assembly, genotype calling in polyploids using POLiMAPS ${ }^{2}$, and linkage mapping using OneMap ${ }^{20}$. First, we removed adapters and low-quality portions of paired-end reads using Trimmomatic (v 0.35$)^{12}$ as described above, and merged the paired-end reads using PEAR (v 0.9.6) ${ }^{21}$ with a minimum overlap size of $20 \mathrm{bp}$. Second, we mapped both the merged and un-merged paired-end reads to the $F$. vesca v 4.1 reference using BWA (v 0.7.12) ${ }^{14}$. The sorted BAM files were generated with SAMtools (v 
1.9) ${ }^{16}$ and then were used to create the mpileup file. Third, with the mpileup file, we conducted polyploid genotype calling using POLiMAPS ${ }^{2}$, in which heterozygous and homozygous loci were identified with the default parameters, except for the depth of $\geq 32 X$ per progeny for the hexaploid. Lastly, to construct maternal and paternal linkage groups (LGs), we assigned SNPs to the most likely LGs based on a logarithm of odds (LOD) threshold of 5 using OneMap ${ }^{20}$ in R (v 3.3.3) $)^{22}$. LGs with at least 20 SNPs were used for subsequent analyses.

To infer the phylogenetic replacement of $F$. moschata in relation to the octoploid strawberry and other diploid Fragaria, we first extracted the quality-filtered reads that contained the above LG SNPs, and mapped these reads to the $F$. vesca $\mathrm{v} 4.1$ reference to generate consensus LG sequences using POLiMAPS. We next used POLiMAPS and the variant call format file described in the above Phylogenomic Analysis of Octoploid Subgenomes section to generate multiple sequence alignments among $F$. moschata $\mathrm{LG}$ sequences, the four octoploid reference subgenomes, diploid Fragaria genomes and the outgroup Potentilla. Phylogenetic inference was conducted for each of chromosomes 1-7 and for maternal and paternal LGs separately, using the ML method with the GTR $+\Gamma$ model and 100 bootstrap replicates in RAxML (v 8.0.26) ${ }^{18}$.

To test the hypothesis of Edger et al. ${ }^{1}$ that $F$. nipponica and $F$. viridis are the progenitors (sister taxa) of the respective 'Camarosa_nipponica' and 'Camarosa_viridis' subgenomes, we built the ML tree of constrained topology that reflects this hypothesis ((Camarosa_nipponica, nipponica),( Camarosa_viridis, viridis),(Camarosa_vesca,bracteata),(Camarosa_iinumae, iinumae)) (Table 3), for each of the seven base chromosomes. These constrained trees were then compared to the ML unconstrained trees using the Shimodaira-Hasegawa (SH) test in RAxML.

To test the hypothesis of Edger et al. ${ }^{1}$ that the hexaploid $F$. moschata is an evolutionary intermediate in the formation of the octoploid strawberry, we built ML trees of constrained 
topologies that reflect this hypothesis (Table 4). Specifically, under this hypothesis, each of the three maternal or paternal LGs should be sister to one of the octoploid subgenomes (i.e.

Camarosa_viridis, Camarosa_iinumae, and Camarosa_nipponica). We built six constraint trees by alternating the combinations of the three LGs and the three octoploid subgenomes, for each of chromosomes 1-7 and for maternal and paternal LGs separately (Table 4). These constrained trees were then compared to the ML unconstrained trees using the SH test in RAxML.

\section{Acknowledgements}

The authors thank Lucas Longway and Rich Cronn for laboratory assistance, Kevin Weitemier and Tara Jennings for assistance with targeted sequence capture, and Katherine Schuller, Elizabeth Jiang, Anna Freundlich and the University of Pittsburgh glasshouse staff for plant cultivation. The OSU Center for Genome Research and Biocomputing conducted Illumina sequencing and provided computational support. This work was funded by the US National Science Foundation (DEB 1241217 to A.L. \& DEB 1020523 to T.L.A.) and the National Natural Science Foundation of China (No. 31261120580 to M.D. and J.L.).

\section{Author Contributions}

Fragaria moschata linkage mapping was conducted by N.W. and T.L.A. Phylogenetic analyses were performed by A.L., N.W., and J.T. Figures were prepared by J.T. and N.W. Sample collection and DNA sequencing in China was led by J.L. and M.D. All authors contributed to the writing and reviewing of the manuscript.

\section{Competing Interests}

The authors declare no competing interests. 


\section{Data Availability}

The sequence alignments and phylogenetic trees will be available on Dryad.

The raw sequence data will be available in the Sequence Read Archive under an NCBI

BioProject.

\section{References}

1. Edger, P. P. et al. Origin and evolution of the octoploid strawberry genome. Nature Genetics 51, 541-547 (2019).

2. Tennessen, J. A., Govindarajulu, R., Ashman, T.-L. \& Liston, A. Evolutionary origins and dynamics of octoploid strawberry subgenomes revealed by dense targeted capture linkage maps. Genome Biology and Evolution 6, 3295-3313 (2014).

3. Kamneva, O. K., Syring, J., Liston, A. \& Rosenberg, N. A. Evaluating allopolyploid origins in strawberries (Fragaria) using haplotypes generated from target capture sequencing. BMC Evolutionary Biology 17, 180 (2017).

4. Yang, Y. \& Davis, T. M. A new perspective on polyploid Fragaria (strawberry) genome composition based on large-scale, multi-locus phylogenetic analysis. Genome Biology and Evolution 9, 3433-3448 (2017).

5. Liston, A., Cronn, R. \& Ashman, T.-L. Fragaria: a genus with deep historical roots and ripe for evolutionary and ecological insights. American Journal of Botany 101, 1686-1699 (2014).

6. Njuguna, W., Liston, A., Cronn, R., Ashman, T.-L. \& Bassil, N. Insights into phylogeny, sex function and age of Fragaria based on whole chloroplast genome sequencing. Molecular Phylogenetics and Evolution 66, 17-29 (2012). 
7. Rousseau-Gueutin, M. et al. Tracking the evolutionary history of polyploidy in Fragaria L. (strawberry): New insights from phylogenetic analyses of low-copy nuclear genes. Molecular Phylogenetics and Evolution 51, 515-530 (2009).

8. Wei, N., Tennessen, J. A., Liston, A. \& Ashman, T.-L. Present-day sympatry belies the evolutionary origin of a high-order polyploid. New Phytologist 216, 279-290 (2017).

9. Dillenberger, M. S., Wei, N., Tennessen, J. A., Ashman, T.-L. \& Liston, A. Plastid genomes reveal recurrent formation of allopolyploid Fragaria. American Journal of Botany 105, 862874 (2018).

10. Van de Peer, Y., Mizrachi, E. \& Marchal, K. The evolutionary significance of polyploidy. Nature Reviews Genetics 18, 411-424 (2017).

11. Wei, N., Cronn, R., Liston, A. \& Ashman, T.-L. Functional trait divergence and trait plasticity confer polyploid advantage in heterogeneous environments. New Phytologist 221, 2286-2297 (2019).

12. Bolger, A. M., Lohse, M. \& Usadel, B. Trimmomatic: a flexible trimmer for Illumina sequence data. Bioinformatics 30, 2114-20 (2014).

13. Buti, M. et al. The genome sequence and transcriptome of Potentilla micrantha and their comparison to Fragaria vesca (the woodland strawberry). GigaScience 7, (2018).

14. Li, H. \& Durbin, R. Fast and accurate short read alignment with Burrows-Wheeler transform. Bioinformatics 25, 1754-1760 (2009).

15. Edger, P. P. et al. Single-molecule sequencing and optical mapping yields an improved genome of woodland strawberry (Fragaria vesca) with chromosome-scale contiguity. GigaScience 7, (2018). 
16. Li, H. et al. The Sequence Alignment/Map format and SAMtools. Bioinformatics 25, 2078-2079 (2009).

17. Pease, J. B. \& Rosenzweig, B. K. Encoding data using biological principles: The multisample variant format for phylogenomics and population genomics. IEEE/ACM Transactions Computational Biology and Bioinformatics 15, 1231-1238 (2018).

18. Stamatakis, A. RAxML version 8: a tool for phylogenetic analysis and post-analysis of large phylogenies. Bioinformatics 30, 1312-1313 (2014).

19. Wei, N. et al. Genetic mapping and phylogenetic analysis reveal intraspecific variation in sex chromosomes of the Virginian strawberry. Journal of Heredity 108, 731-739 (2017).

20. Margarido, G. R. A., Souza, A. P. \& Garcia, A. A. F. OneMap: software for genetic mapping in outcrossing species. Hereditas 144, 78-79 (2007).

21. Zhang, J. J., Kobert, K., Flouri, T. \& Stamatakis, A. PEAR: a fast and accurate Illumina Paired-End reAd mergeR. Bioinformatics 30, 614-620 (2014).

22. R Core Team. R: A language and environment for statistical computing. (R Foundation for Statistical Computing. https://www.R-project.org/, 2017). 
Table 1: Summary of recent hypotheses for the diploid ancestors of the wild octoploid strawberries, Fragaria virginiana and F. chiloensis. These two species were introduced to Europe and hybridized approximately 270 years ago, creating $F$. ×ananassa, the cultivated strawberry (reviewed in ref. ${ }^{5}$ ). Phylogenetic analyses support a single origin between 0.43-1.62 million years ago ${ }^{9}$. Kamneva et al. $^{3}$ found no evidence for additional progenitors beyond $F$. vesca and $F$. iinumae, and while their results were consistent with $3 F$. iinumae-like subgenomes, this could not be directly evaluated. Yang and Davis ${ }^{4}$ proposed an additional unknown progenitor, and questioned whether each subgenome had a single diploid ancestry. The A,B,C,D genome designations are to provide a common reference, and were not used in these studies.

\begin{tabular}{|l|l|l|l|l|}
\hline genome A & genome B & genome C & genome D & authors \\
\hline vesca & iinumae & iinumae- & iinumae- & This study \\
\hline vesca & & related & related & \\
\hline vesca & iinumae & nipponica & viridis & Edger et al. 2019 \\
\hline $\begin{array}{l}\text { vesca } \\
\text { vesca }\end{array}$ & iinumae & bucharica & viridis & Yang \& Davis 2017 \\
\hline & & & & \\
\hline
\end{tabular}


Table 2: New sequences reported here. Detailed locality data is available at http://wildstrawberry.org

\begin{tabular}{|c|c|c|c|c|c|c|}
\hline & voucher name & sequencing & reads & $\begin{array}{l}\text { estimated } \\
\text { genome } \\
\text { coverage } \\
\text { for WGS } \\
\text { samples }\end{array}$ & $\begin{array}{l}\text { percent } \\
\text { mapped } \\
\text { reads for } \\
\text { targeted }\end{array}$ & NCBI SRR \\
\hline F. vesca bracteata & NA.OR.4.18.5 & WGS & 20641086 & 10 & & \\
\hline F. iinumae & JP.HK.3.25.3 & WGS & 19026532 & 9 & & \\
\hline F. mandshurica & CH.HL.8.13.1 & WGS & 44180874 & 32 & & \\
\hline F. nilgerrensis & CH.YN.7.1.4 & WGS & 32261034 & 23 & & \\
\hline F. nipponica & JP.HK.6.17.5 & WGS & 21047026 & 10 & & \\
\hline F. viridis & CH.XJ.4.7.3 & WGS & 38332552 & 27 & & \\
\hline F. moschata & EU.SI.1.27.1 & targeted & 2161806 & & $94.48 \%$ & \\
\hline F. moschata & EU.SI.1.29.2 & targeted & 2536263 & & $94.18 \%$ & \\
\hline F. moschata $\mathrm{F} 1$ & MOSXB.105 & targeted & 3825308 & & $88.64 \%$ & \\
\hline F. moschata $\mathrm{F} 1$ & MOSXB.108 & targeted & 4073659 & & $85.90 \%$ & \\
\hline F. moschata $\mathrm{F} 1$ & MOSXB.109 & targeted & 3305483 & & $87.16 \%$ & \\
\hline F. moschata $\mathrm{F} 1$ & MOSXB.10 & targeted & 3636198 & & $86.98 \%$ & \\
\hline F. moschata $\mathrm{F} 1$ & MOSXB.112 & targeted & 4624772 & & $84.64 \%$ & \\
\hline F. moschata $\mathrm{F} 1$ & MOSXB.117 & targeted & 5141669 & & $86.52 \%$ & \\
\hline F. moschata F1 & MOSXB.118 & targeted & 3593912 & & $85.85 \%$ & \\
\hline F. moschata $\mathrm{F} 1$ & MOSXB.119 & targeted & 4184427 & & $85.57 \%$ & \\
\hline F. moschata F1 & MOSXB.11 & targeted & 4729689 & & $86.89 \%$ & \\
\hline F. moschata $\mathrm{F} 1$ & MOSXB.122 & targeted & 4056714 & & $86.03 \%$ & \\
\hline F. moschata $\mathrm{F} 1$ & MOSXB.130 & targeted & 3954656 & & $86.31 \%$ & \\
\hline F. moschata F1 & MOSXB.132 & targeted & 4614820 & & $83.42 \%$ & \\
\hline F. moschata F1 & MOSXB.13 & targeted & 3906454 & & $86.03 \%$ & \\
\hline F. moschata F1 & MOSXB.149 & targeted & 3687513 & & $85.02 \%$ & \\
\hline F. moschata $\mathrm{F} 1$ & MOSXB.14 & targeted & 3112895 & & $88.49 \%$ & \\
\hline F. moschata F1 & MOSXB.150 & targeted & 3854800 & & $86.50 \%$ & \\
\hline
\end{tabular}




\begin{tabular}{|c|c|c|c|c|}
\hline F. moschata $\mathrm{F} 1$ & MOSXB.151 & targeted & 3757039 & $88.81 \%$ \\
\hline F. moschata F1 & MOSXB.152 & targeted & 3620346 & $86.94 \%$ \\
\hline F. moschata F1 & MOSXB.15 & targeted & 4009303 & $85.89 \%$ \\
\hline F. moschata $\mathrm{F} 1$ & MOSXB.165 & targeted & 4074828 & $85.56 \%$ \\
\hline F. moschata $\mathrm{F} 1$ & MOSXB.167 & targeted & 4011845 & $85.28 \%$ \\
\hline F. moschata $\mathrm{F} 1$ & MOSXB.168 & targeted & 3437484 & $86.12 \%$ \\
\hline F. moschata F1 & MOSXB.179 & targeted & 3728707 & $86.00 \%$ \\
\hline F. moschata $\mathrm{F} 1$ & MOSXB.180 & targeted & 3183301 & $87.41 \%$ \\
\hline F. moschata $\mathrm{F} 1$ & MOSXB.182 & targeted & 3163260 & $85.99 \%$ \\
\hline F. moschata $\mathrm{F} 1$ & MOSXB.183 & targeted & 3148561 & $85.94 \%$ \\
\hline F. moschata $\mathrm{F} 1$ & MOSXB.187 & targeted & 3094357 & $85.07 \%$ \\
\hline F. moschata $\mathrm{F} 1$ & MOSXB.19 & targeted & 5047685 & $84.97 \%$ \\
\hline F. moschata $\mathrm{F} 1$ & MOSXB.23 & targeted & 3587588 & $86.51 \%$ \\
\hline F. moschata F1 & MOSXB.25 & targeted & 3363580 & $85.84 \%$ \\
\hline F. moschata F1 & MOSXB.26 & targeted & 4217917 & $86.24 \%$ \\
\hline F. moschata $\mathrm{F} 1$ & MOSXB.27 & targeted & 3472967 & $84.89 \%$ \\
\hline F. moschata $\mathrm{F} 1$ & MOSXB.33 & targeted & 3679616 & $85.06 \%$ \\
\hline F. moschata $\mathrm{F} 1$ & MOSXB.35 & targeted & 2869162 & $84.43 \%$ \\
\hline F. moschata F1 & MOSXB.36 & targeted & 4025962 & $87.28 \%$ \\
\hline F. moschata $\mathrm{F} 1$ & MOSXB.37 & targeted & 2835874 & $86.94 \%$ \\
\hline F. moschata $\mathrm{F} 1$ & MOSXB.39 & targeted & 3235333 & $89.72 \%$ \\
\hline F. moschata $\mathrm{F} 1$ & MOSXB.40 & targeted & 4300475 & $85.22 \%$ \\
\hline F. moschata $\mathrm{F} 1$ & MOSXB.48 & targeted & 3134614 & $86.49 \%$ \\
\hline F. moschata F1 & MOSXB.71 & targeted & 4471722 & $85.82 \%$ \\
\hline F. moschata F1 & MOSXB.72 & targeted & 5257489 & $83.67 \%$ \\
\hline F. moschata F1 & MOSXB.7 & targeted & 3265668 & $84.28 \%$ \\
\hline F. moschata F1 & MOSXB.80 & targeted & 4261215 & $84.99 \%$ \\
\hline F. moschata F1 & MOSXB.8 & targeted & 4500479 & $85.32 \%$ \\
\hline F. moschata F1 & MOSXB.93 & targeted & 2448916 & $86.26 \%$ \\
\hline F. moschata $\mathrm{F} 1$ & MOSXB.97 & targeted & 4255696 & $85.32 \%$ \\
\hline
\end{tabular}


Table 3: Shimodaira-Hasegawa (SH) tests support an alternative scenario of the evolutionary origins of the octoploid strawberry, relative to the hypothesis of Edger et al. (2019).

\begin{tabular}{|c|c|c|c|c|c|c|c|c|}
\hline & $\begin{array}{c}\text { Chromo } \\
\text { some } \\
\end{array}$ & 1 & 2 & 3 & 4 & 5 & 6 & 7 \\
\hline ML unconstrained tree & $-\log _{\mathrm{e}} L$ & 43776167 & 53635963 & 67303204 & 58266330 & 53739632 & 72891475 & 43776415 \\
\hline \multicolumn{9}{|l|}{ Edger et al. (2019) hypothesis } \\
\hline $\begin{array}{l}\text { (Camarosa_vesca,bracteata), } \\
\text { (Camarosa_iinumae,iinumae), } \\
\text { (Camarosa_viridis,viridis), } \\
\text { (Camarosa_nipponica,nipponic } \\
\text { a) }\end{array}$ & $\Delta-\log _{e} L$ & $158226^{* *}$ & $219842^{* *}$ & $198938^{* *}$ & $190332^{* *}$ & $192305^{* *}$ & $245147^{* *}$ & $114341^{* *}$ \\
\hline
\end{tabular}

- $\log _{\mathrm{e}} L$ : negative $\log$ likelihood; $\Delta-\log _{\mathrm{e}} L$ : the difference in $-\log _{\mathrm{e}} L$ between the best ML constraint tree and the ML unconstrained tree for each of chromosomes 1-7.

The $P$ values of the SH tests are denoted as asterisks: ${ }^{* *}, P<0.01$. 
Table 4: Shimodaira-Hasegawa (SH) tests do not support the hypothesis that the hexaploid Fragaria moschata was the evolutionary intermediate of the octoploid strawberry, as evidenced by moschata maternal LGs (m1-m3) and paternal LGs (p1-p3).

\begin{tabular}{|c|c|c|c|c|c|c|c|c|}
\hline & $\begin{array}{l}\text { Chromo } \\
\text { some }\end{array}$ & 1 & 2 & 3 & 4 & 5 & 6 & 7 \\
\hline \multicolumn{9}{|l|}{ Maternal } \\
\hline ML unconstrained tree & $-\log _{\mathrm{e}} L$ & 89129 & 278511 & 208456 & 213813 & 206867 & 392846 & 215159 \\
\hline \multicolumn{9}{|l|}{ Constrained trees } \\
\hline $\begin{array}{l}((\text { Camarosa_viridis,m1),(Cama } \\
\text { rosa_iinumae,m2),(Camarosa_ } \\
\text { nipponica,m3)); }\end{array}$ & $\Delta-\log _{\mathrm{e}} L$ & - & $831^{* *}$ & $685^{* *}$ & $558^{* *}$ & $341^{* *}$ & $761^{* *}$ & $104^{* *}$ \\
\hline $\begin{array}{l}\text { ((Camarosa_viridis,m1),(Cama } \\
\text { rosa_iinumae,m3),(Camarosa_ } \\
\text { nipponica,m2)); }\end{array}$ & $\Delta-\log _{\mathrm{e}} L$ & - & $846^{* *}$ & $381^{* *}$ & $559^{* *}$ & $341^{* *}$ & $751^{* *}$ & $100^{* *}$ \\
\hline $\begin{array}{l}((\text { Camarosa_viridis,m2),(Cama } \\
\text { rosa_iinumae,m1),(Camarosa_ } \\
\text { nipponica,m3)); }\end{array}$ & $\Delta-\log _{\mathrm{e}} L$ & - & $831^{* *}$ & $715^{* *}$ & $543^{* *}$ & $337^{* *}$ & $809^{* *}$ & $134^{* *}$ \\
\hline $\begin{array}{l}((\text { Camarosa_viridis,m2),(Cama } \\
\text { rosa_iinumae,m3),(Camarosa_ } \\
\text { nipponica,m1)); }\end{array}$ & $\Delta-\log _{\mathrm{e}} L$ & - & $846^{* *}$ & $715^{* *}$ & $567^{* *}$ & $382^{* *}$ & $809^{* *}$ & $425^{* *}$ \\
\hline $\begin{array}{l}((\text { Camarosa_viridis,m3),(Cama } \\
\text { rosa_iinumae,m1),(Camarosa_ } \\
\text { nipponica,m2)); }\end{array}$ & $\Delta-\log _{\mathrm{e}} L$ & - & $928^{* *}$ & $643^{* *}$ & $544^{* *}$ & $337^{* *}$ & $750^{* *}$ & $131^{* *}$ \\
\hline $\begin{array}{l}((\text { Camarosa_viridis,m3),(Cama } \\
\text { rosa_iinumae,m2),(Camarosa_ } \\
\text { nipponica,m1)); }\end{array}$ & $\Delta-\log _{\mathrm{e}} L$ & - & $922^{* *}$ & $684^{* *}$ & $568^{* *}$ & $382^{* *}$ & $760^{* *}$ & $153^{* *}$ \\
\hline
\end{tabular}




\section{Paternal}

ML unconstrained tree

$-\log _{\mathrm{e}} L \quad 87227$

211795

215665

208624

382540

Constrained trees

((Camarosa_viridis,p1),(Cama rosa_iinumae,p2),(Camarosa_ nipponica,p3));
$\Delta-\log _{\mathrm{e}} L \quad-$
$1033^{* *}$
$1024^{* *}$
$1461^{* *}$
$1112^{* *}$
$1542^{* *}$
$1113^{* *}$

((Camarosa_viridis,p1),(Cama rosa_iinumae,p3),(Camarosa_ nipponica,p2));

\begin{tabular}{|c|c|c|c|c|c|c|c|}
\hline$\Delta-\log _{\mathrm{e}} L$ & - & $1046^{* *}$ & $1028^{* *}$ & $1290^{* *}$ & $1112^{* *}$ & $1522^{* *}$ & $882^{* *}$ \\
\hline$\Delta-\log _{\mathrm{e}} L$ & - & $1072^{* *}$ & $1172^{* *}$ & $1478^{* *}$ & $1114^{* *}$ & $1562^{* *}$ & $1136^{* *}$ \\
\hline$\Delta-\log _{\mathrm{e}} L$ & - & $1068^{* *}$ & $1176^{* *}$ & $1290^{* *}$ & $1141^{* *}$ & $1547^{* *}$ & $884^{* *}$ \\
\hline$\Delta-\log _{e} L$ & - & $1046^{* *}$ & $1013^{* *}$ & $1478^{* *}$ & $755^{* *}$ & $1504^{* *}$ & $860^{* * *}$ \\
\hline$\Delta-\log _{\mathrm{e}} L$ & - & $1030^{* *}$ & $1041^{* *}$ & $1461^{* *}$ & $755^{* *}$ & $1528^{* *}$ & $862^{* *}$ \\
\hline
\end{tabular}

((Camarosa_viridis,p2),(Cama rosa_iinumae,p1),(Camarosa_ nipponica,p3));

((Camarosa_viridis,p2),(Cama rosa_iinumae,p3),(Camarosa_ nipponica,p1));

((Camarosa_viridis,p3),(Cama rosa_iinumae,p1),(Camarosa_ nipponica,p2));

((Camarosa_viridis,p3),(Cama rosa_iinumae,p2),(Camarosa_ nipponica,p1));

$-\log _{e} L:$ negative $\log$ likelihood; $\Delta-\log _{e} L:$ the difference in $-\log _{e} L$ between the best ML constraint tree and the ML unconstrained tree for each of chromosomes $1-7$. The $P$ values of the SH tests are denoted as asterisks: ${ }^{* *}, P<0.01$. The maternal ML unconstrained tree for each of chromosomes 1-7 can be found in Figure 1b and Supplementary Figure 3. Because there was only one maternal LG 
for chromosome 1, the SH test was not performed. In chromosomes 5 and 6, maternal LG m3 was missing. The paternal ML unconstrained tree for each of chromosomes 1-7 can be found in Figure 1b and Supplementary Figure 4. Because there was only one paternal LG for chromosome 1, the SH test was not performed. 

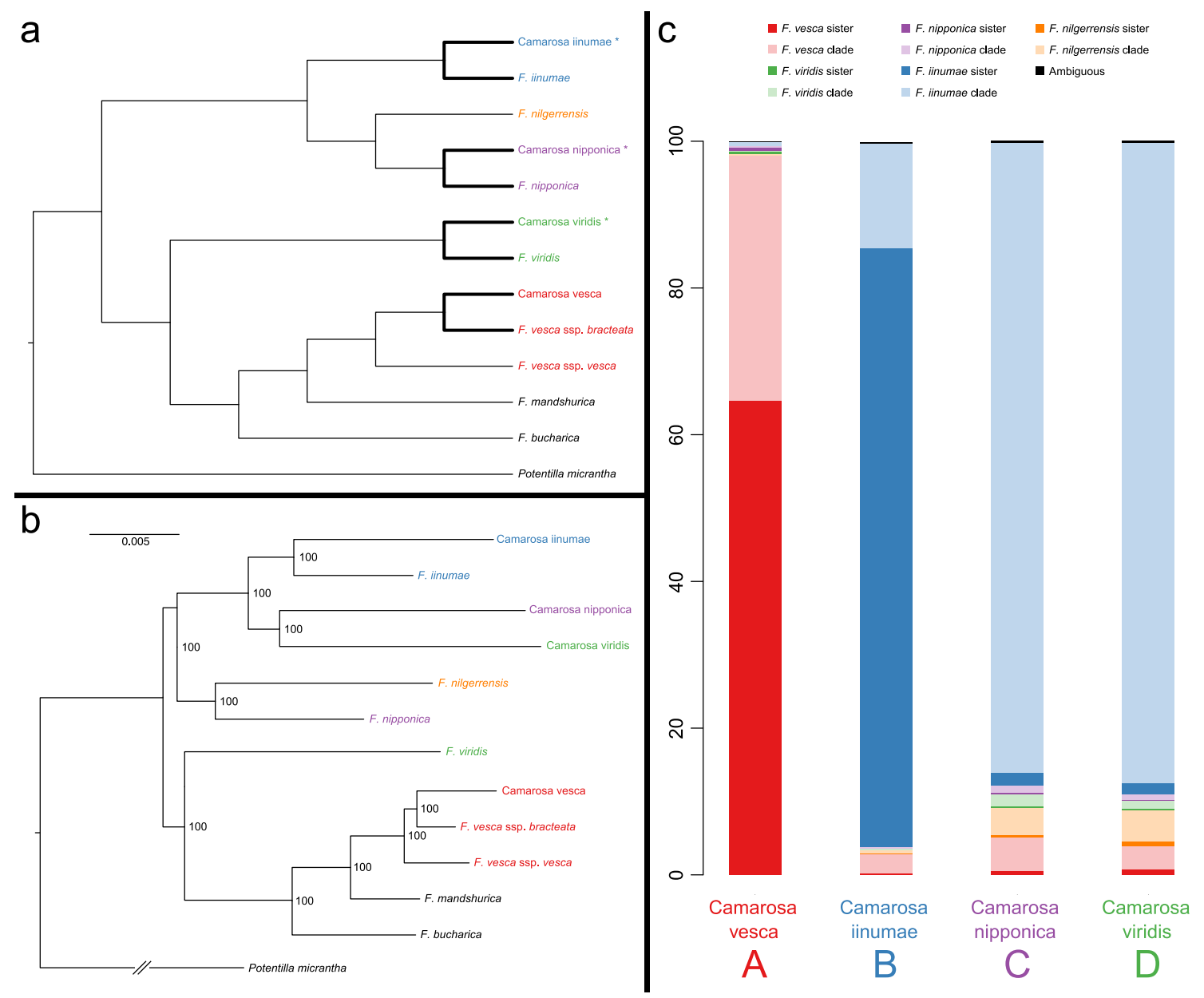

Figure 1. Phylogenomics of octoploid subgenomes. a, The phylogenetic hypothesis presented by Edger et al. ${ }^{1}$ suggesting that each octoploid subgenome has a different extant diploid progenitor, and that three of these subgenomes (denoted by asterisks) comprise the hexaploid species $F$. moschata. The bold lines represent the topology constraint we applied in the Shimodaira-Hasegawa test of the Edger et al. ${ }^{1}$ hypothesis vs. our phylogenomic results (Table 3 ). b, Maximum likelihood estimate of phylogeny for base chromosome 1, all nodes have $100 \%$ bootstrap support. This topology is shared by five of the seven chromosomes (Fig 1). c, Summary of the phylogenetic positions of the four octoploid subgenomes in maximum likelihood estimates of phylogeny in 2191 non-overlapping windows of $100 \mathrm{~kb}$ across the 7 base 
chromosomes. The octoploid subgenomes A 'Camarosa vesca' and B 'Camarosa iinumae'

generally are sister to their eponymous diploids $F$. vesca (red) and $F$. iinumae (blue). In contrast, subgenome C 'Camarosa nipponica' and subgenome D 'Camarosa viridis', predominantly share a most recent common ancestor (clade) with F. iinumae (light blue). See Fig. 3 for an explanation of the sister vs. clade categorization and the results for all 2191 windows. For data sources and phylogenetic methods, see Materials and Methods. 
2

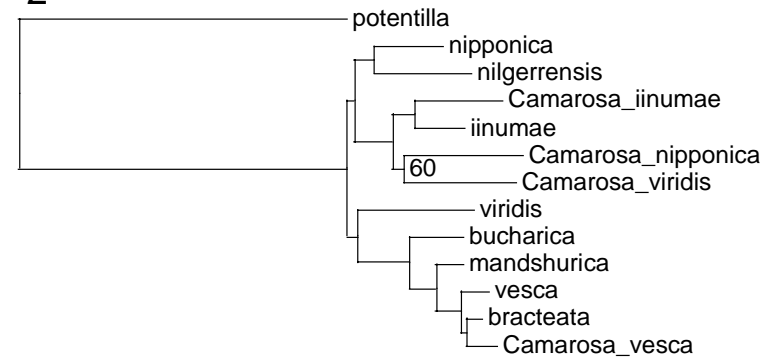

4

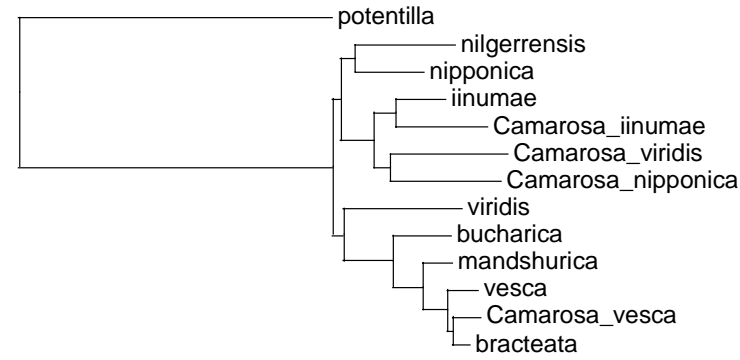

6

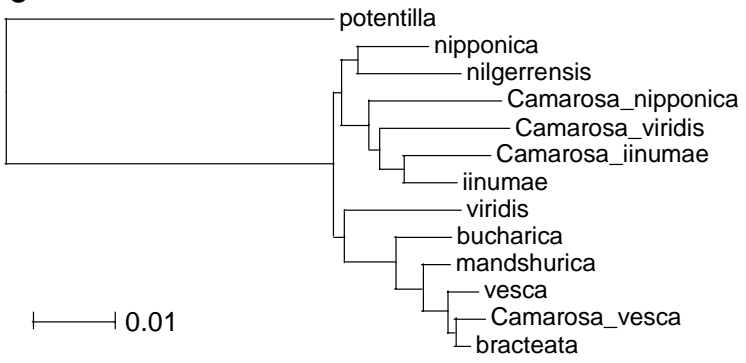

3

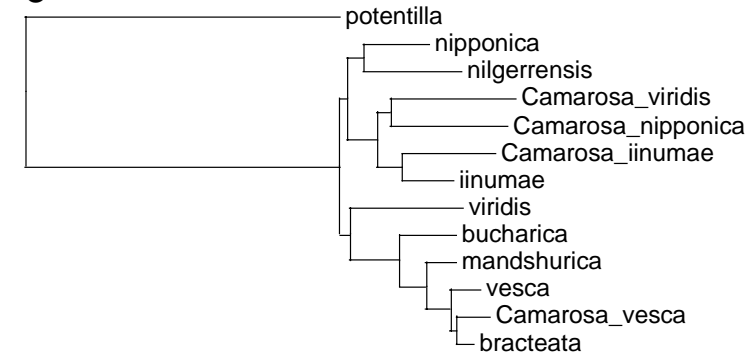

5

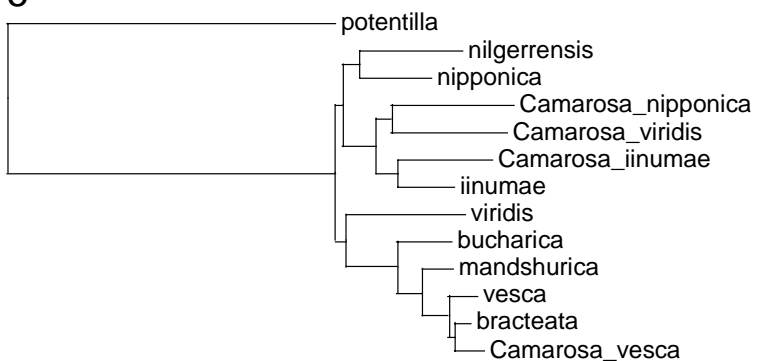

7

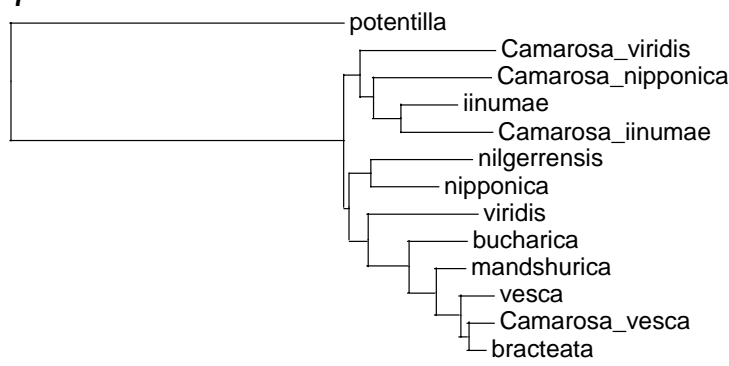

Figure 2: Maximum likelihood estimate of phylogeny for base chromosomes 2-7. Bootstrap

values for all nodes are $100 \%$, unless indicated. 
bioRxiv preprint doi: https://doi.org/10.1101/665216; this version posted June 11,2019 . The copyright holder for this preprint (which was not certified by peer review) is the author/funder, who has granted bioRxiv a license to display the preprint in perpetuity. It is made available under aCC-BY 4.0 International license.

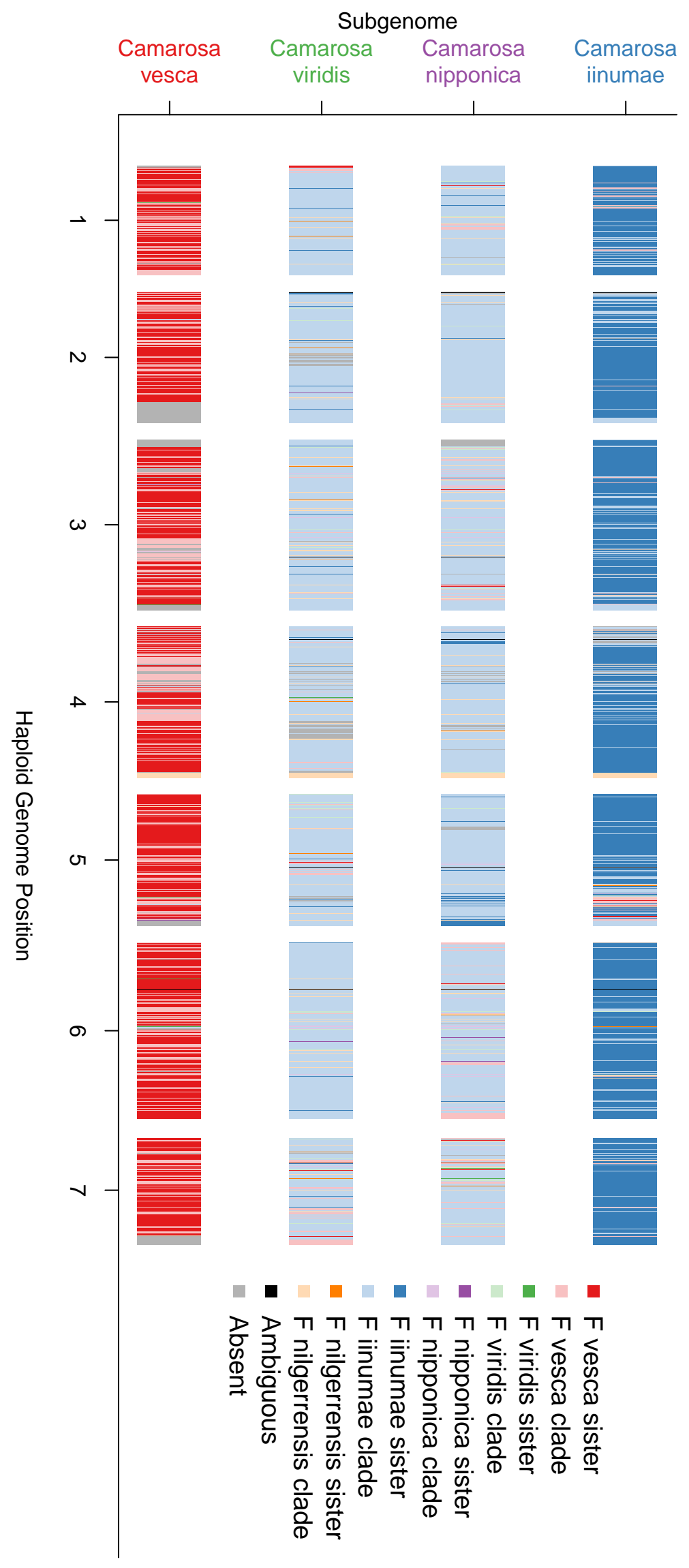


Figure 3: Phylogenetic positions of the four octoploid subgenomes in maximum likelihood estimates of phylogeny in 2191 non-overlapping windows of $100 \mathrm{~kb}$ across the 7 base

chromosomes. Phylogenetic matrices averaged 89077 nucleotides per $100 \mathrm{~kb}$ window

(Supplementary Table 1). For each window, we recorded the diploid species sharing the most recent common ancestor (MRCA) with each octoploid subgenome, and we further noted when this diploid was "sister" to that subgenome. If the MRCA diploid was not sister to that subgenome, we labelled these as "clade". This generally occurred when subgenomes were sister to each other, e.g. 'Camarosa viridis' and 'Camarosa nipponica' in Fig. 1b. The two subspecies of $F$. vesca and the closely related $F$. mandshurica and $F$. bucharica were grouped together for MRCA scoring, and combined into a single color category. We restricted the category "vesca sister" to windows where the octoploid subgenome is sister to one subspecies of $F$. vesca; all other positions were scored as "vesca clade". More than one diploid species shared a MRCA with multiple subgenomes in $0.2 \%$ of the 2191 trees, and these were labelled "ambiguous". When an octoploid subgenome was excluded from a $100 \mathrm{kbp}$ window (<10\% of aligned sites) it was scored "absent". These regions primarily correspond to large duplications, e.g. at the 3' end of chromosome 2 and 7 in the F. vesca subgenome. 
bioRxiv preprint doi: https://doi.org/10.1101/665216; this version posted June 11, 2019. The copyright holder for this preprint (which was not certified by peer review) is the author/funder, who has granted bioRxiv a license to display the preprint in perpetuity. It is made available under aCC-BY 4.0 International license.

1

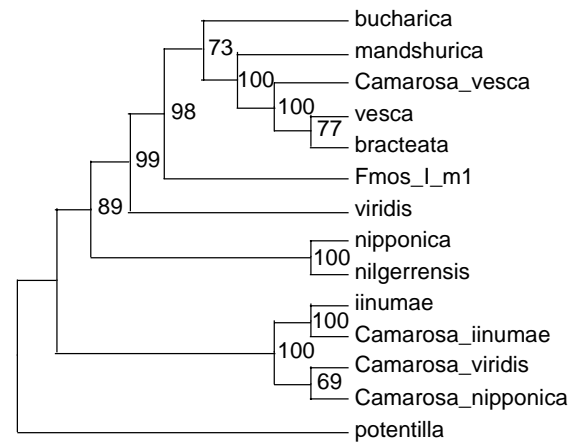

3

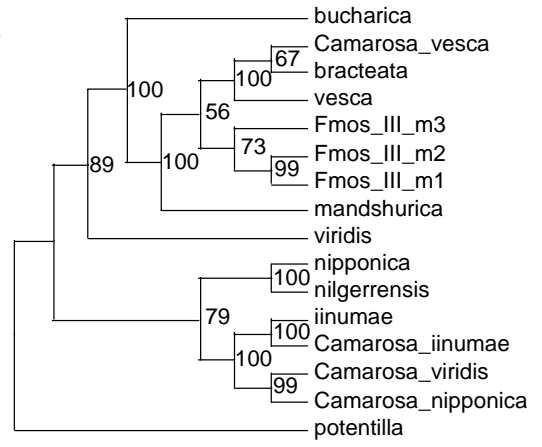

5

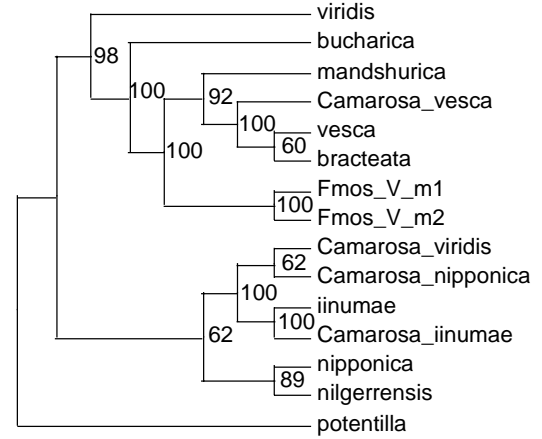

7

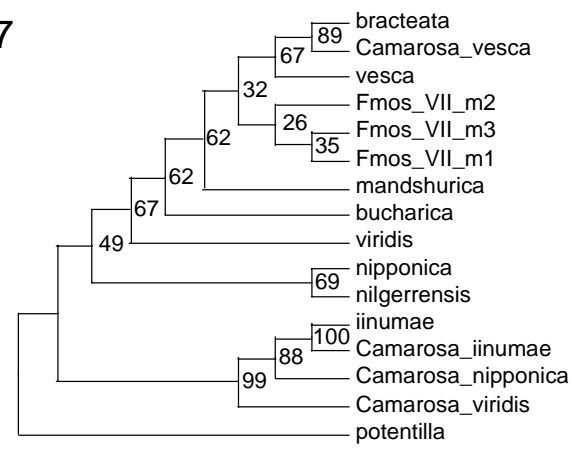

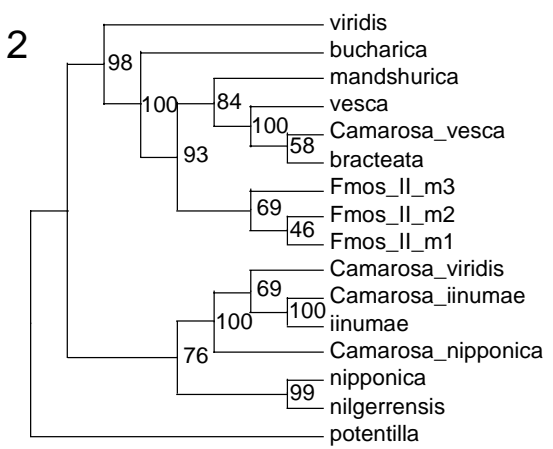
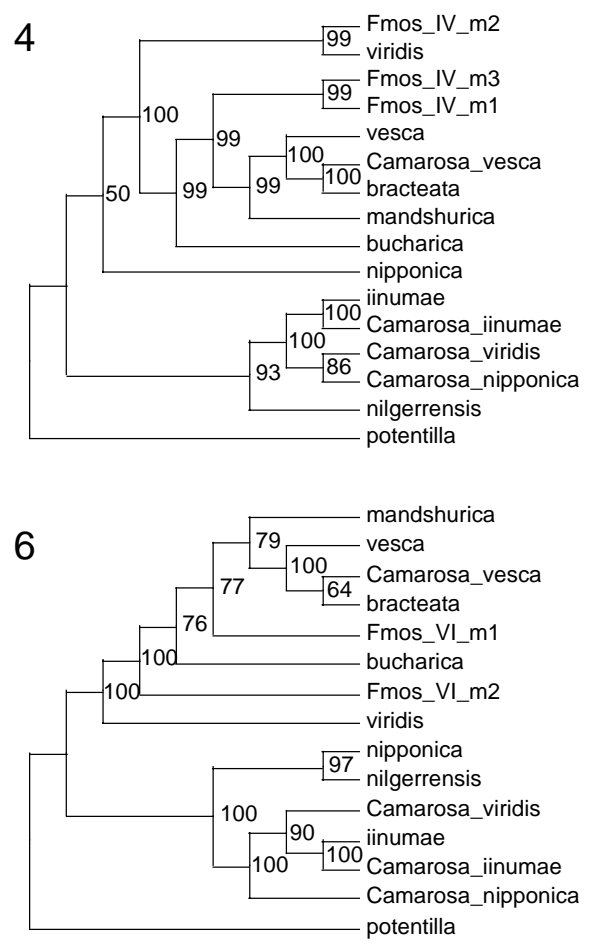

Figure 4: Maximum-likelihood phylogenies of base chromosomes 1-7 involving the maternal linkage groups (LGs) of the hexaploid Fragaria moschata. These LGs are named 
after species ('Fmos'), chromosome (I-VII), maternal map (m) and LG number (1-3). Some

chromosomes (e.g. 1, 5 and 6) have incomplete $F$. moschata LG numbers. Numbers associated with branches are ML bootstrap support values from 100 replicates. 

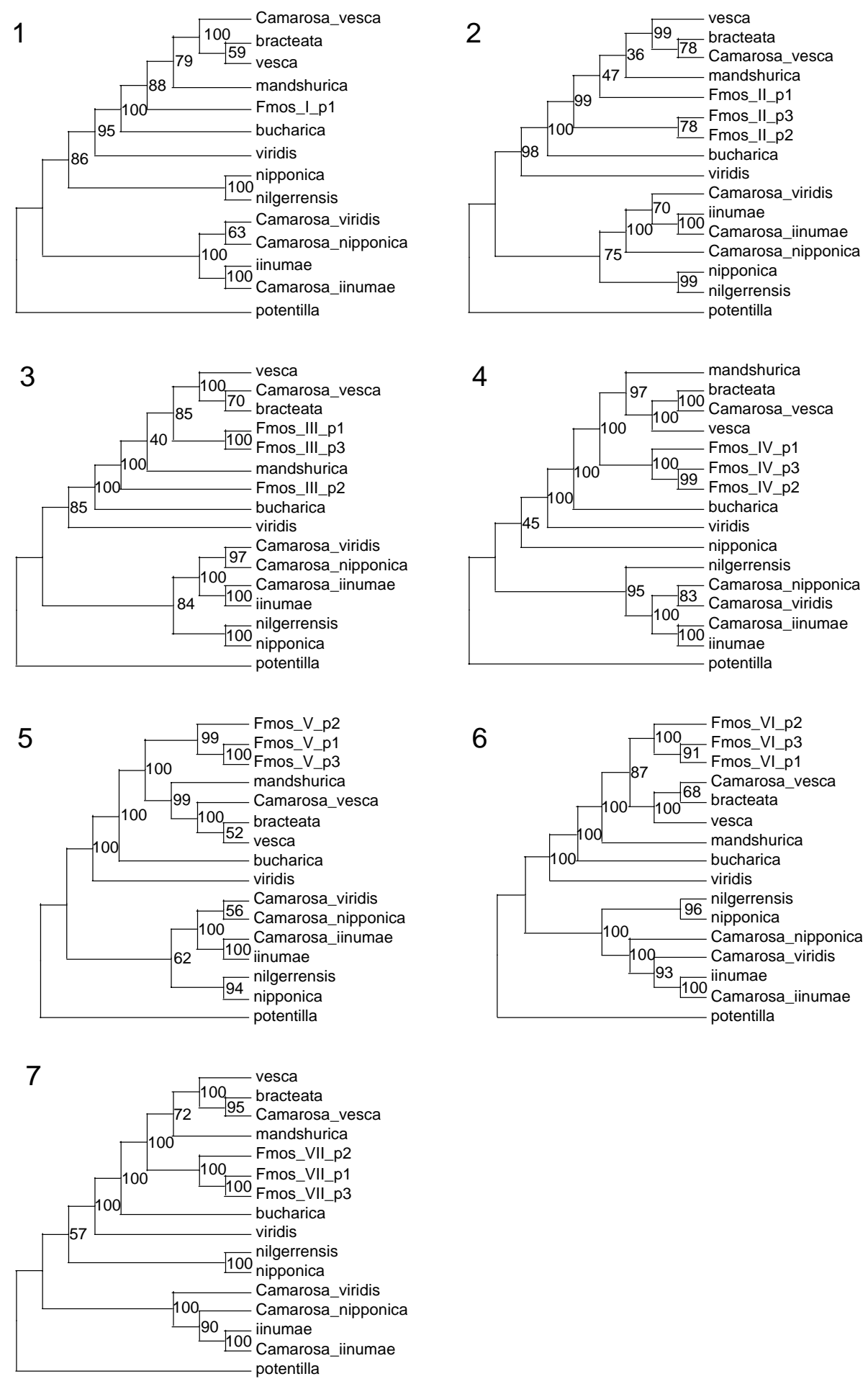

Figure 5: Maximum-likelihood phylogenies of base chromosomes 1-7 involving the paternal linkage groups (LGs) of the hexaploid Fragaria moschata. These LGs are named after species ('Fmos'), chromosome (I-VII), paternal map (p) and LG number (1-3). 

aCC-BY 4.0 International license.

Chromosome 1 has incomplete F. moschata LG numbers. Numbers associated with branches are

ML bootstrap support values from 100 replicates. 